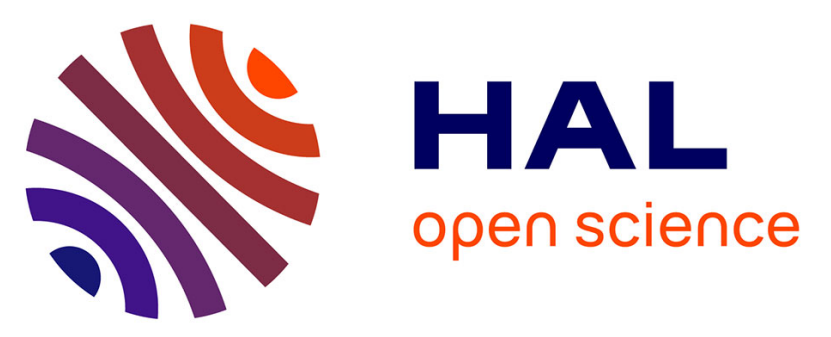

\title{
Social Factory Architecture: Social Networking Services and Production Scenarios Through the Social Internet of Things, Services and People for the Social Operator 4.0
}

David Romero, Thorsten Wuest, Johan Stahre, Dominic Gorecky

\section{- To cite this version:}

David Romero, Thorsten Wuest, Johan Stahre, Dominic Gorecky. Social Factory Architecture: Social Networking Services and Production Scenarios Through the Social Internet of Things, Services and People for the Social Operator 4.0. IFIP International Conference on Advances in Production Management Systems (APMS), Sep 2017, Hamburg, Germany. pp.265-273, 10.1007/978-3-319-66923-6_31. hal-01666177

\section{HAL Id: hal-01666177 \\ https://hal.inria.fr/hal-01666177}

Submitted on 18 Dec 2017

HAL is a multi-disciplinary open access archive for the deposit and dissemination of scientific research documents, whether they are published or not. The documents may come from teaching and research institutions in France or abroad, or from public or private research centers.
L'archive ouverte pluridisciplinaire HAL, est destinée au dépôt et à la diffusion de documents scientifiques de niveau recherche, publiés ou non, émanant des établissements d'enseignement et de recherche français ou étrangers, des laboratoires publics ou privés.

\section{(c)(1)}

Distributed under a Creative Commons Attribution| 4.0 International License 


\title{
Social Factory Architecture: Social Networking Services and Production Scenarios through the Social Internet of Things, Services and People for the Social Operator 4.0
}

\author{
David Romero $^{1-2}$, Thorsten Wuest ${ }^{3}$, \\ Johan Stahre ${ }^{4}$, Dominic Gorecky ${ }^{5}$ \\ ${ }^{1}$ Tecnológico de Monterrey, Mexico \\ ${ }^{2}$ Griffith University, Australia \\ david.romero.diaz@gmail.com \\ ${ }^{3}$ West Virginia University, USA \\ thwuest@mail.wvu.edu \\ ${ }^{4}$ Chalmers University of Technology, Sweden \\ johan.stahre@chalmers.se \\ ${ }^{5}$ Switzerland Innovation, Switzerland \\ dominic.gorecky@switzerland-innovation.com
}

\begin{abstract}
The prevailing industrial digitalisation flagship initiative, Industrie 4.0, gathers a substantial part of its functionality from the human in the system. This will drive a need for focus on both human and social dimensions of technology. The paper explores the roles of the Social Operator 4.0 in smart and social factory environments, where humans, machines and software systems will cooperate (socialise) in real-time to support manufacturing and services operations. A Social Factory Architecture based on adaptive, collaborative and intelligent multi-agent system is proposed for enabling such cooperation. Further, production scenarios are proposed, to show how social operators, social machines, and social software systems will communicate and cooperate via enterprise social networking services to accomplish production goals in the Social Internet of Things, Services and People.
\end{abstract}

Keywords: Industry 4.0, Operator 4.0, Social Internet of Things, Services and People, Smart Wearables, Smart Machines, Social Assets, Enterprise Social Networking Services.

\section{Introduction}

Industry 4.0 will allow new forms of interaction between humans, machines and software systems. Such phenomenon are known as the industrial Internet of Things, Services and People (IoTSP), where interconnecting things, services and people via the Internet will improve data analysis, optimise operations, boost productivity and flexibility, enhance reliability, save energy and costs, and generate innovative e-services for smart factory environments [1].

Smart devices and smart wearables, such as data goggles or tablets, will increasingly make it possible for humans to interact with so-called "social machines", and powerful social (assistance) software systems (e.g. artificial intelligence, virtual assistants, and chatbots) will guide operators in increasingly complex cyber-physical systems (CPSs), including smart machines and supply chains, as temporarily equal partners at the shop-floor [2]. 
Moreover, with the emergence of the Social Internet of Industrial Things (SIoIT), manifested as smart machines with social properties (context awareness and cooperative initiates), namely "social assets", such will share their status information (e.g. location, condition, and availability) and cooperate via enterprise social networks to achieve a common goal, an optimal smart factory production system [3].

This paper explores the role of the Social Operator 4.0 in the context of smart and social factory environments, where humans, machines and software systems will cooperate (socialise) in real-time to support manufacturing and services operations. Furthermore, a high-level Social Factory Architecture based on an 'adaptive, collaborative and intelligent multi-agent system' will be introduced in this paper as a proposal to enable such cooperation, as well as, some production scenarios envisioning how social operators, social machines and social software systems will communicate and cooperate with each other via enterprise social networking services to accomplish production goals in the Social Internet of Things, Services and People.

\section{The Social Operator 4.0 and its Social Companions}

An Operator 4.0 is defined as "a smart and skilled operator who performs not only 'cooperative work' with robots, but also 'work aided' by machines as and if needed, by means of human cyber-physical systems, advanced human-machine interaction technologies and adaptive automation towards 'human-automation symbiosis work systems'" [4]. Moreover, a Social Operator 4.0 is a type of Operator 4.0 [4] that uses smart wearable solutions together with advanced human-machine interaction (HMI) technologies to cooperate with other 'social operators', 'social machines' and 'social software systems' in order to communicate and exchange information for mutual benefit and align/alter activities as well as share resources so that more efficient results can be achieved at the smart and social factory of Industry 4.0.

With the emergence of smarter factory environments and the Social Operator 4.0, smart wearable solutions [5], HMI technologies [6], and adaptive automation strategies [7] will play a significant role when combining different interaction mechanisms and sharing and trading control strategies between social operators, social machines and social software systems towards a 'social factory' [8].

A Social Factory is a live enterprise social network with powerful middleware and analytics backend to improve the connection between social operators, social machines and social software systems working together in a smart production environment, and the data created within the networking process [8] towards a sustainable 'learning factory' [9] [10].

According to [8], a social factory should be able to (a) provide the right information and the right time and place (anywhere and anytime) to the right person, machine and/ or software, (b) support humans under any working conditions, (c) engage humans to contribute to new knowledge creation, (d) treat humans, machines and software as equal partners, and (e) learn from all this socialization of knowledge by explicitising it.

In this context, the faithful social companions of the Social Operator 4.0 will be other social operators, social machines and social software systems. The Social Operator will be able to interact with these other social entities, communicate and exchange information, align or alter activities, share resources, and work together on joint tasks. 


\section{Social Factory Architecture: Components \& Technologies}

The Next Generation Balanced Automated Production Systems [11] [12] consist of 'hardware' (e.g. machine tools and robots), 'software' (e.g. enterprise information systems) and 'humanware' (e.g. blue-collar and white-collar workers) components coexisting with mechanical and human autonomy as well as with human-machine collaboration capabilities where autonomy and synergies between human, machines and systems create a social sustainable and competitive factory. The next subsections will detail selected areas of relevance.

\subsection{Hardware: Smart Wearable Solutions and the Internet of Things (IoT)}

Several smart wearable solutions, part of the IoTSP paradigm, have been designed for a variety of purposes as well as for wear on a variety of parts of the body, such as head, eyes, wrist, waist, hands, fingers, legs, or embedded into different elements of attire [5] in order to tech-augment operators physical, sensorial and cognitive capabilities [12].

Similarly, a diversity of 'things' has been embedded with electronics, software, sensors, actuators and network connectivity in order to augment their capabilities. Such is the case of smart machines, now capable of operating autonomously (intelligence), avoid and correct processing errors (security), learn and anticipate future events (management), and interact with other machines and systems (connectivity) [13].

\subsection{Software: Actively Adaptive Agents for Human-Automation Symbiosis}

The essence of Agent Technology (AT) is to mediate interaction between human beings and technological artefacts. Hence, AT has been considered an important approach for developing socially sustainable factories, where human agents can cooperate (socialise) with other human agents and artificial (machine) agents as hybrid agents and emerging agents to keep their agenthood [12], and therefore optimally leverage human skills and automation capabilities at the shop-floor in order to provide human inclusiveness and harness the strengths of human beings and machines to achieve new levels of efficiency and productivity that neither can achieve alone [14] and that not compromise production objectives [12].

Agents' Agenthood is defined by Wooldridge \& Ciancarini [15], "as a system with the following properties: autonomy, reactivity, pro-activeness and social ability".

According to Yamasaki [16] in $\mathrm{Xu}$ et al. [17], an Active Interface is "a type of human-machine (agent) interface that does not only wait for users' explicit input but also tries to get information from users' implicit input, and external environment. Based on the gathered information, it acts spontaneously and keeps the system in advantageous conditions for its users", with users being human agents or artificial (machine) agents in this case. Furthermore, an (active) Interface Agent "can learn by continuously 'looking over the shoulder' of the user as he/she/it performs actions against other artefacts, and provide the users with 'adaptive aiding' as well as of alternating the activities instead of human" [18]. In this sense, a human or machine in the physical world will coexist with its associate human or artificial (machine) agent (a.k.a. digital 'agent' twin) in a cyber-physical environment, so that as an intelligent 
agent can evolve by itself as a human or machine user's proficient level improves [18]. For humans, such learning/ evolution could be tracked by means of Advanced Trained Classifiers (ATC) [19] [20], while for machines the use of different Machine Learning Techniques (MLT) [21] might be considered.

The use of intelligent and actively adaptive collaborative multi-agent system to coordinate the support of manufacturing and services operations at the shop-floor is proposed to achieve human-automation symbiosis [11] [12] at the social factory and its smart production environment. In such a set-up, active interfaces within the social IoTSP of the factory, as interface agents, will allow to gather information from the social operators, social machines and social software systems agenthood status and send a request for cooperation (i.e. to create a hybrid or emergent agent) to other human or artificial (machine) agents in order to keep their agenthood, and therefore production running.

In this sense, the social factory should be considered as a 'collaborative environment of intelligent multi-agents' [22], where (real) humans and machines 'twin agents' use interface agents to facilitate communication between them and the cyber and physical worlds, and other agents such as broker agents support tasks allocation and control sharing \& trading [23] in the cyber-physical production environment. Fig. 1 presents a high-level Social Factory Architecture based on an Adaptive, Collaborative and Intelligent Multi-Agent System (ACI-MAS).

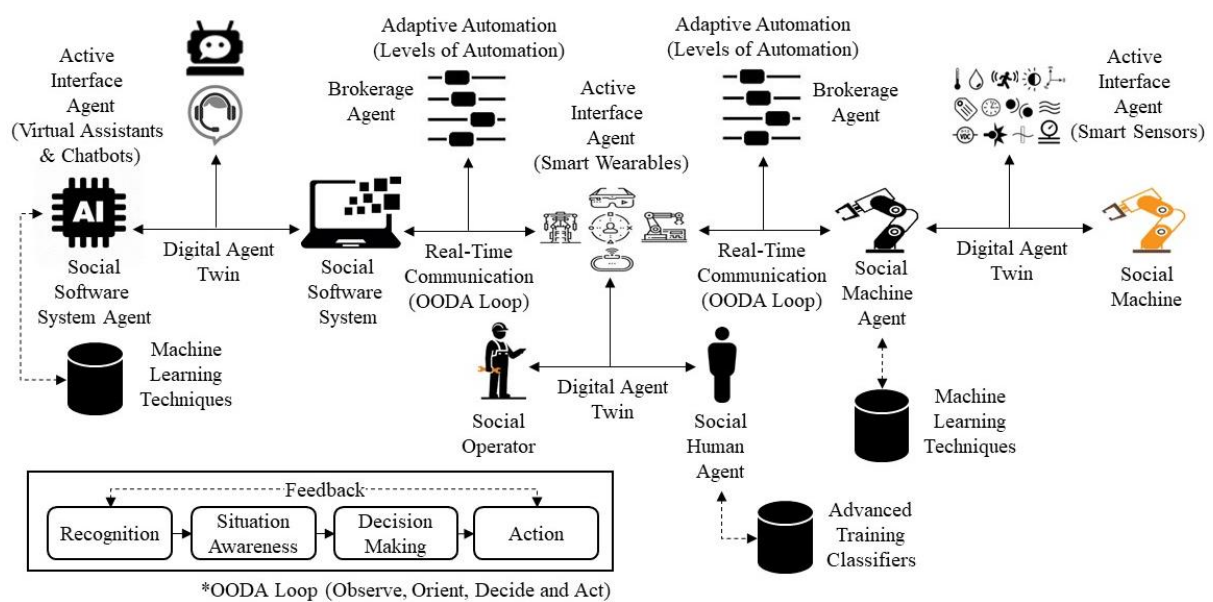

Fig. 1. High-level Social Factory Architecture based on an ACI-MAS

Such intelligent MAS architecture will aim to (a) facilitate communication between the social operators, social machines and social software systems, (b) assist them to distribute tasks (based on their competences) and share \& trade control in collaborative tasks, (c) maintain as much as possible human inclusiveness without compromising production objectives, and (d) record and track humans and machines evolution as their proficient levels improve through learning and practice.

The following agents will operate in the social factory fulfilling different roles:

- Human agents - represent the humans and their capabilities in the system and are a duo consisting of human + interface agent, which allows a human to interface with the rest of the system. 
- Artificial (machine) agents - represent the machines and their capabilities in the system and are a duo consisting of machine + interface agent, which allows a machine to interface with the rest of a system.

- (active) Interface agents - represent a set of interaction rules and conditions for supporting humans and machines interfacing with the rest of a system; their 'active' feature allows the interface agent to constantly learn and evolve its rules by being trained by observation, imitation, feedback and/ or programming in order to be able to personalise the assistance to its user (viz. human or artificial (machine) agent) [24] and such assistance be provided in an adaptive and dynamic manner, and only when required, to help the human or machine in difficulty to main his/her/its 'agenthood' at the tasks at hand by different automation or mechanisation invocation strategies [11] [12] (e.g. critical-event, measurement-based and/or modellingbased strategies [23]).

- Broker agents - represent the (adaptive) levels of automation [25] [26] (viz. adaptive automation) available in the system and the rules for sharing and trading control in human-machine cooperation in order to efficiently allocate labour (cognitive and physical) and distribute tasks between the automated part and the humans at the workstations of an adaptive production system [11] [12] [27].

\subsection{Humanware: The Human Factor in Adaptive Automation Systems}

Humanware is defined as "a function of 'leadership', 'followership' and the reciprocal interaction between the two, where leadership is a leader's willingness to fulfil both task accomplishment and group maintenance and followership is followers' voluntary desire to follow their leader and to achieve their tasks" [28].

In the social factory, the Social Operator 4.0 will be empowered with technology (e.g. smart wereables and other devices) and thus encourage collaboration with other social operators, social machines and social software systems. At the same time, the Social Operator 4.0 will be monitored with the help of ATCs [19] [20] and other detecting and preventing error approaches like "digital poka-yokes" [4] [29] for 'poor humanware' (i.e. wilful transgression, risk-taking, peer acceptance of poor humanware [28]) in order to avoid human error (i.e. perception, judgment, action errors) and provide a virtual safety net.

In this context, the main goal of adaptive automation, based on active interface agents and brokerage agents, is to prevent errors and to reduce out-of-the-loop performance of the humanware by preserving an adequate level of situation awareness and mental workload [30], while providing a crucial perception of empowerment materialised into an appropriate level of freedom [31] for the social operator [4] [12].

\section{Enterprise Social Networking Services \& Production Scenarios}

Enterprise Social Networking Services (E-SNS) focus on "the use of mobile and social collaborative and interface methods to connect the smart (social) operators at the shop-floor with the smart (social) factory resources, including other social operators, social machines and social software system. Such connections include 
'social relations' among the workforce ( $c f$. social network services) and between social operators and smart (social) things and services ( $c f$. Social IoTSP [1]) to interact, share and create information for decision-making support and/or alignment or altering of activities and their related resources to achieve a compatible or common goal" [Extended from 4].

In this case, the social operator is considered the main focus and the following scenarios are always centred on the Social Operator 4.0. While there are many other scenarios (e.g. Social Machine to Social Machine) possible and worthwhile to be analysed, this is not the focus of this research work.

\subsection{Social Operator Networking Scenarios}

One of the possible collaboration scenarios is a Social Operator interacting with other social operators. In such, a Social Operator to (one or many) Social Operator scenario, the use of adapted social network services like a B2B Facebook or Twitter that are capable to facilitate, e.g., one-to-many communication, incorporate location based services and real-time sharing of media (viz. audio, picture, video) or allow for facilitating a dynamic community based capability matrix. Such E-SNS, supported by an intelligent and actively adaptive collaborative MAS, can enable opportunities and real-time multimedia communication (viz. images, holograms, video, audio and text) capabilities between social operators using smart wearables (viz. MS-HoloLens) that can empower the workforce to communicate and contribute with their expertise to different problem-solving scenarios at the shop-floor by bringing together the right people with the right information and the right time to address a situation without certain limitations (e.g. different location of expert and to be solved problem).

\subsection{Social Machine Networking Scenarios}

Enhancing the 'senses' of the Social Operator 4.0 through, e.g. smart wearable tech, enables her/him/it to engage in social interaction and communication with social machines within the E-SNS. SIoIT can connect, through 'interactive machine learning', smart (social) operators with smart (social) things ( $c f$. intelligent assets) in social networks for sharing information and exchanging messages about their location, condition, operation status and availability for improving (for example) at machine level the asset reliability (e.g. intelligent maintenance) and at production line level the material flows and resources productivity (e.g. spotting bottle-necks) towards social problems-solving and optimisation of the production system.

\subsection{Social Software Systems Networking Scenarios}

Similarly to the Social Operator 4.0 interacting with social machines ( $c f$. intelligent assets), being 'always-on' and connected enables the social operator to naturally engage in communication with social software systems. This can be envisioned as a 'virtual assistant' with an Artificial Intelligence (AI) backend, like IBM Watson, where the social operator can either actively ask questions that the system will answer based on available information/data or, passively, the social software system might monitor the environment and behaviour and provide pro-active information and/or decision making support through voice, video or holographic communication channels. 


\section{Conclusions}

This paper is suggesting a Social Operator 4.0 concept in the context of smart and social factory environments. Furthermore, a high-level Social Factory Architecture based on an adaptive, collaborative and intelligent multi-agent system was introduced taking advantage of a 'multi-agent approach' for interconnecting and interoperating multiple agents across an enterprise social network to provide solutions by means of temporary collaborations (viz. hybrid and emerging agents) in situations where expertise and capabilities are spatially distributed. Finally, some production scenarios envisioning how the Social Operator 4.0 will communicate and interact with other social operators, social machines and social software systems have been presented.

\section{References}

1. ABB: http://new.abb.com/about/technology/iotsp - Internet of Things, Services \& People.

2. Federal Ministry for Economic Affairs and Energy: Industrie 4.0 Platform: Aspects of the Research Roadmap in Application Scenarios - White Paper (2016)

3. Li, H., Parlikad, A.K.: Social Internet of Industrial Things for Industrial and Manufacturing Assets. 3rd IFAC Workshop on Advanced Maintenance Engineering, Service and Technology, Vol. 49, Issue 28, pp. 208-213 (2016)

4. Romero, D., Stahre, J., Wuest, T., Noran, O., Bernus, P., Fast-Berglund, Å., Gorecky, D.: Towards an Operator 4.0 Typology: A Human-Centric Perspective on the Fourth Industrial Revolution Technologies. Int'l Conf. on Computers \& Industrial Engineering (CIE46) Proceedings, Tianjin/China, pp. 1-11 (2016).

5. Perera, C., Liu, C.H., Jayawardena, S.: The Emerging Internet of Things Marketplace from an Industrial Perspective: A Survey. IEEE Transactions on Emerging Topics in Computing, 3(4):585-598 (2015)

6. Gorecky, D., Schmitt, M., Loskyll, M., Zühlke, D.: Human-Machine-Interaction in the Industry 4.0 Era. 12th IEEE Int'1 Conf. on Industrial Informatics, pp. 289-294 (2014)

7. Hancock, P.A., Jagacinski, R.J., Parasuraman, R., Wickens, C.D., Wilson, G.F., Kaber, D.B.: Human-Automation Interaction Research: Past, Present and Future. Ergonomics in Design, 21(2):9-14 (2013)

8. Kassner, L., Hirmer, P., Wieland, M., Steimle, F., Königsberger, J., Mitschang, B.: The Social Factory: Connecting People, Machines and Data in Manufacturing for Context Aware Exception Escalation. Proceedings of the 50th Hawaii Int'l Conf. on System Sciences (2017)

9. Gröger, C., Kassner, L.B., Hoos, E., Königsberger, J., Kiefer, C., Silcher, S., Mitschang, B.: The Data-Driven Factory - Leveraging Big Industrial Data for Agile, Learning and Human-Centric Manufacturing. Proceedings of the 18th Int'l Conf. on Enterprise Information Systems (2016)

10. Gorecky, D. Mura, K., Arlt, F.: A Vision on Training and Knowledge Sharing Applications in Future Factories. 12th IFAC Symposium on Analysis, Design, and Evaluation of Human-Machine Systems Vol. 12, Part 1, pp. 90-97 (2013)

11. Romero, D., Noran, O., Stahre, J., Bernus, P., Fast-Berglund, Å.: Towards a HumanCentred Reference Architecture for Next Generation Balanced Automation Systems: Human-Automation Symbiosis. Advances in Production Management Systems, 460:556$566(2015)$

12. Romero, D.; Bernus, P.; Noran. O.; Stahre, J. and Fast-Berglund, Å.: The Operator 4.0: Human Cyber-Physical Systems \& Adaptive Automation towards Human-Automation Symbiosis Work Systems. Production Management Initiatives for a Sustainable World, IFIP AICT 488, pp. 677-686 (2016) 
13. Arrow ECS e-Magazine.: What Makes a Smart Machine Smart? (2016) $\mathrm{http}: / /$ ecsnamagazine.arrow.com/what-makes-a-smart-machine-smart/

14. Prof. Julie Shah: Interactive Robotics Group, MIT (2014) http://www.robotics.org/content-detail.cfm/Industrial-Robotics-Industry-Insights/TheRealm-of-Collaborative-Robots-Empowering-Us-in-Many-Forms/content_id/4854

15. Wooldridge, M.J., Ciancarini, P.: Agent-Oriented Software Engineering: The State of the Art. 1st Int'l Workshop on Agent-Oriented Software Engineering (AOSE), pp. 1-28, Springer Verlag (2000)

16. Yamasaki, N., Anzai, Y.: Active Interface for Human-Robot Interaction. IEEE Int'l Conf. on Robotics and Automation, Japan, 3: 3103-3109 (1995)

17. Xu, Y., Ohmoto, Y., Ueda, K., Komatsu, T., Okadome, T., Kamei, K., Okada, S., Sumi, Y., Nishida, T.: Actively Adaptive Agent for Human-Agent Collaborative Task. Active Media Technology: 5th Int'l Conf., AMT, Beijing, J. Liu et al., LNCS 5820, pp. 19-30 (2009)

18. Sawaragi, T., Ogura, T.: Concept Sharing between Human and Interface Agent under Time Criticality. Advances in Networked Enterprises: Virtual Organizations, Balanced Automation, and Systems Integration, 269-278 (2000)

19. Willson, G.F., Russel, C.A.: Performance Enhancement in a UAV Task Using Psychophysiologically determined Adaptive Aiding. Human Factors, 49(6):1005-1019 (2007)

20. Woźniak, M., Graña, M., Corchado, E.: A Survey of Multiple Classifier Systems as Hybrid Systems. Information Fusion, 16: 3-17 (2014)

21. Wuest, T., Weimer, D., Irgens, C., Thoben, K-D.: Machine Learning in Manufacturing: Advantages Challenges and Applications. Production \& Manufacturing Research, 4(1):2345 (2016)

22. Zhang, C., Xi, J., Yang, X.: An Architecture for Intelligent Collaborative Systems based on Multi-Agent, 12th Int'l Conf. on CSCWD (2008)

23. Inagaki, T.: Adaptive Automation: Sharing and Trading of Control. Chapter 8 - Handbook of Cognitive Task Design, pp. 147-169 (2003)

24. Maes, P.: Social Interface Agents: Acquiring Competence by Learning from Users and others Agents. AAAI Spring Symposium, 71-58, Stanford University, California, US (1994)

25. Hancock, P.A., Jagacinski, R.J., Parasuraman, R. et al.: Human-Automation Interaction Research: Past, Present and Future. Ergonomics in Design, 21(2):9-14 (2013)

26. Sheridan, T., Parasuraman, R.: Human-Automation Interaction. Human Factors and Ergonomics, 1(1):89-129 (2006)

27. Calefato, C., Montanari, R., Tesauri, F.: The Adaptive Automation Design. Human Computer Interaction: New Developments, InTech, pp. 141-154 (2008)

28. Nishigaki, S., Vavrin, J., Kano, N., Haga, T., Kunz, J.C., Law, K.: Humanware, Human Error, and Hiyari-Hat: A Template of Unsafe Symptoms. Journal of Construction Engineering and Management, 120(2):421-442 (1994)

29. Stewart, D.M., Grout, J.R.: The Human Side of Mistake-Proofing. Production and Operations Management, 10(4):440-459 (2001)

30. Endsley, M.: Toward a Theory of Situation Awareness in Dynamic Systems. Human Factors - Human Factors and Ergonomics Society, 37(1), pp. 32-64 (1995)

31. Kaber, D.B., Riley, J.M., Tan, K., Endsley, M.R: On the Design of Adaptive Automation for Complex Systems. Int'1. J. of Cognitive Ergonomics, 5(1):37-57 (2001) 